\title{
АРХЕОЛОГИЯ
}

DOI: http://dx.doi.org/10.15688/jvolsu4.2016.3.1

UDC 902/904

Submitted: 10.03.2016

LBC 63.4

Accepted: 02.04.2016

\section{ON THE CHRONOLOGICAL ASPECT OF PRODUCTIVE ECONOMY ORIGIN IN THE LOWER VOLGA REGION ${ }^{1}$}

\author{
Aleksandr A. Vybornov \\ Volga Region State Academy of Social Sciences and Humanities, Samara, Russian Federation \\ Markku Oinonen \\ University of Helsinki, Helsinki, Finland \\ Natalia S. Doga \\ Volga Region State Academy of Social Sciences and Humanities, Samara, Russian Federation
}

Marianna A. Kulkova

Herzen State Pedagogical University, Saint Petersburg, Russian Federation

\section{Aleksandr S. Popov}

Volga Region State Academy of Social Sciences and Humanities, Samara, Russian Federation

\begin{abstract}
The Lower Volga region territory plays a large part in studying the origin of producing economy. It is particularly important to determine the time of this process commencement. The researchers assumed the coexistence of the late Neolithic and Early Eneolithic monuments in this area. On that basis they highlighted the Neo-Eneolithic period. The researchers dated it to the middle of the 5 millennium BC. They associated this period and the emergence of producing economy at the territory under discussion. The weak point of this hypothesis was a small number of radiocarbon dates on this issue. Obtained after 2007, the radiocarbon dates on the Neolithic and Eneolithic monuments in the Lower Volga region demonstrate a 500-year chronological gap between them. That is why the hypothesis of the Neo-Eneolithic period is not confirmed. At the same time there is a reason to believe that the Late Neolithic and the Caspian Sea region culture coexisted during 5800-5500 BC. However, the referring of the Caspian Sea region culture to the Eneolithic suffers from the lack of evidence that its carriers were familiar with metal. There is also no evidence that they had cattle breeding. The situation changed after studying the Oroshaemoye I archaeological site in the Lower Volga region in 2014-2015. Cultural layer with materials from only the Caspian Sea region culture was found there. This increases the significance of the monument. The bones of domestic sheep and goats were found in this cultural layer. This is the first significant evidence of producing economy existing among the population of the Lower Volga region. AMS radiocarbon dates 4800 and $4700 \mathrm{BC}$ were obtained from domestic sheep bones from this site. Thus, it is possible to make a reasoned conclusion that producing economy had being formed in the Lower Volga region among the carriers of the Caspian Sea region culture. This process can be reliably dated to the beginning of the 5 millennium BC.
\end{abstract}

Key words: Lower Volga region, Neo-Eneolithic period, producing economy, chronology, culture of the Caspian Sea region. 


\title{
О ХРОНОЛОГИЧЕСКОМ АСПЕКТЕ ПРОИСХОЖДЕНИЯ ПРОИЗВОДЯЩЕГО ХОЗЯЙСТВА В НИЖНЕМ ПОВОЛЖЬЕ ${ }^{1}$
}

\author{
Александр Алексеевич Выборнов \\ Поволжская государственная социально-гуманитарная академия, г. Самара, Российская Федерация \\ Маркку Ойнонен \\ Университет Хельсинки, г. Хельсинки, Финляндия \\ Наталья Сергеевна Дога \\ Поволжская государственная социально-гуманитарная академия, г. Самара, Российская Федерация

\section{Марианна Алексеевна Кулькова} \\ Российский государственный педагогический университет, г. Санкт-Петербург, Российская Федерация
}

\section{Александр Сергеевич Попов}

Поволжская государственная социально-гуманитарная академия, г. Самара, Российская Федерация

Аннотация. Территория Нижнего Поволжья играет большую роль в изучении происхождения производящего хозяйства. Особое значение имеет установление времени начала этого процесса. Исследователи предполагали сосуществование памятников позднего неолита и раннего энеолита в этом регионе. На этом основании они выделяли нео-энеолитический период. Исследователи датировали его серединой $\mathrm{V}$ тыс. до н. э. Они связывали с этим периодом возникновение производящего хозяйства на интересуемой территории. Слабой стороной этой гипотезы было единичное количество радиоуглеродных дат по данному аспекту. Полученная после 2007 г. серия радиоуглеродных дат по памятникам неолита и энеолита Нижнего Поволжья свидетельствует о хронологическом разрыве между ними в 500 лет, поэтому гипотеза о нео-энеолитическом периоде не получает подтверждения. В то же время есть основания предполагать сосуществование позднего неолита и прикаспийской культуры в интервале 5800-5500 лет ВС. Однако отнесение прикаспийской культуры к энеолиту осложняется отсутствием доказательств знакомства ее носителей с металлом. Не было свидетельств о наличии у них скотоводства. Изучение стоянки Орошаемое I в 2014-2015 гг. в Нижнем Поволжье изменило ситуацию. Здесь обнаружен культурный слой с материалами только прикаспийской культуры. Это повышает значение памятника. В культурном слое обнаружены кости домашних овцы и козы. Это первое достоверное доказательство наличия производящего хозяйства у населения Нижнего Поволжья. По костям домашней овцы с этой стоянки на АМС получены радиоуглеродные даты - 4800 и 4700 лет ВС. Таким образом, можно сделать аргументированный вывод о том, что производящее хозяйство формируется в Нижнем Поволжье у носителей прикаспийской культуры. Этот процесс можно достоверно относить к началу V тыс. до н. э.

Ключевые слова: Нижнее Поволжье, нео-энеолитический период, производящее хозяйство, хронология, прикаспийская культура.

Территория Нижнего Поволжья является одной из важнейших для изучения проблем южного неолита и эпохи раннего металла. Особое значение для этой проблематики имеет вопрос о происхождении производящего хозяйства. Эта тема многогранна, и поэтому в данной работе будут рассмотрены только периодизационный и хронологический аспекты.
В начале XXI в. Д.Я. Телегин поставил вопрос о существовании нео-энеолитического периода на территории Поднепровья. Он опирался на данные о сосуществовании пришлой трипольской культуры с местным неолитическим населением [18, с. 114-118]. По мнению ученого, период нео-энеолита укладывается в интервал от последней четверти VI до последней четверти V тыс. до н. э. 
Д.Я. Телегин предложил эту модель для решения проблем хронологии неолита и энеолита и на территориях от Дона до Волги [18, c. 120]. А.Т. Синюк применительно к материалам Среднего Подонья относит начало пережиточно неолитического этапа к середине V тыс. до н. э. и предлагает перенести эти реалии на всю зону восточноевропейской лесостепи $[17$, с. 201]. Что касается территории степного Поволжья, то А.И. Юдин использует более узкое понятие нео-энеолитического периода. Автор на основании совместного залегания материалов орловской неолитической и прикаспийской энеолитической культур на Варфоломеевской стоянке делает вывод об их одновременности [22, c. 5]. Однако решение столь важного вопроса затруднялось противоречивостью немногочисленных радиоуглеродных дат. Для позднего неолита и раннего энеолита (верхний и слой $2 \mathrm{~A}$ Варфоломеевской стоянки) начиная с 2007 г. были получены новые даты по керамике и нагару, которые распределились в широком хронологическом интервале от середины VI до начала V тыс. до н. э. [15, c. 258]. Даты по керамике прикаспийской культуры стоянок Буровая 41 и КурпежеМолла в Северном Прикаспии укладываются в интервал от второй четверти до конца VI тыс. до н. э. [9, с. 193]. Из этого А.И. Юдин делает вывод, что поздненеолитическое и раннеэнеолитическое население Нижнего Поволжья сосуществовало довольно значительное время $[21$, с. 28$]$. Различие концепций Д.Я. Телегина и А.И. Юдина заключается в том, то первый считает сосуществование неолитических и энеолитических признаков пережиточным этапом неолита, а второй говорит о новом этапе энеолита. Эту точку зрения поддержал И.Н. Наумов. Проанализировав радиоуглеродные датировки памятников Нижнего Подонья и Нижнего Поволжья, автор сделал вывод о том, что неолитические культуры региона бытуют в VII - первой половине $\mathrm{V}$ тыс. до н. э., а на рубеже VI-V тыс. до н. э. на Нижней Волге появляются энеолитические памятники. С этого времени и до середины V тыс. до н. э. в регионе сосуществовали разнокультурные пережиточно неолитические и энеолитические стоянки. Этот период исследователь и именует неолито-энеолитическим [14, с. 17-19]. Схожей точки зрения придерживается П.М. Кольцов. Автор относит материалы поздненеолитической стоянки Тентексор в Северном Прикаспии к «пережиточному» неолиту. Основанием для этого явился преимущественно хронологический аспект: дата по Тентексору относится к середине V тыс. до н. э. [12, с. 130131], а временные рамки хвалынской энеолитической культуры укладываются в интервал от начала до середины V тыс. до н. э. Следует отметить, что все вышеперечисленные гипотезы базировались на крайне ограниченном количестве радиоуглеродных дат. С 2007 г. началось датирование керамики, что позволило резко увеличь базу данных по радиоуглеродным датам для памятников неолита-энеолита Поволжья. Так, для поздненеолитической стоянки Тентексор было получено несколько дат по разным материалам, которые фиксируют середину VI тыс. до н. э. $[2$, c. 258]. Иначе говоря, это древнее хвалынской культуры на 500 лет и тентексорское население не могло сосуществовать с энеолитическим. Но в тоже время для материалов прикаспийской культуры были получены значения от второй четверти до конца VI тыс. до н. э. На этом основании А.А. Выборнов выдвигает предположение о частичном сосуществовании памятников прикаспийского типа и неолитического населения с накольчатой посудой на территории Северного Прикаспия во второй четверти VI тыс. до н. э. $[8$, с. 60]. Однако среди исследователей нет единого мнения относительно периодизационной принадлежности прикаспийской культуры. Одни специалисты считали ее позденеолитической $[13$, с. $13-14]$, а другие раннеэнеолитической $[7 ; 20]$. Кроме того, есть точка зрения о том, что воротничковые материалы прикаспийской культуры синхронны хвалынской культуре развитого энеолита [5].

Для эпохи энеолита, по мнению отечественных специалистов, характерны два маркера: наличие металла и производящего хозяйства. Что касается первого признака, то, по мнению В.В. Ставицкого, ситуация весьма неоднозначна. Так, нам неизвестны металлические изделия на памятниках мариупольской культурной общности, за исключением единичных предметов в Никольском 
могильнике. Можно лишь отметить, что находки из металла так же малочисленны и на памятниках трипольской культуры, энеолитическая принадлежность которой не ставится под сомнение после находки Карбунского клада. Но трипольских погребений значительно меньше, чем мариупольских. Металлические изделия появляются только в хвалынских могильниках $[18$, с. 32]. Что касается прикаспийской культуры, то на ее памятниках до сих пор металлических предметов не обнаружено.

Не менее сложным представляется вопрос о наличии производящего хозяйства у населения неолита и энеолита интересуемой территории. У ряда специалистов не вызывает сомнений отсутствие домашних животных на Варфоломеевской стоянке Нижнего Поволжья [10, с. 26]. Исследования в 2013-2015 гг. новых неолитических памятников в Северном Прикаспии и степном Поволжье также не выявили доместицированной фауны [11, с. 79 $90 ; 16$, c. 237]. Что касается его южной части, то на стоянке Тентексор П.А. Косинцевым была определена одна кость домашней овцы [23, p. 69]. Если она принадлежит материалам позднего неолита, то можно было бы сделать предположение о формировании производящего хозяйства на данной территории именно в это время. Однако ее достоверная принадлежность к неолиту нуждалась в дополнительной аргументации. Подтверждением могла послужить именно хронология. Если дата по кости домашней овцы совпала бы со значениями по другим материалам, полученным для стоянки Тентексор, то ее принадлежность к неолиту стала бы очевидной. Уместно напомнить, что по различным органическим веществам в разных лабораториях (включая АМС) для стоянки Тентексор получена серия совпадающих радиоуглеродных дат, фиксирующая вторую четверть VI тыс. до н. э. [2, с. 258]. По кости домашней овцы на АMC в лаборатории университета г. Хельсинки профессором М. Ойноненом получена дата 3555 лет ВС $(4555 \pm 30$ BP, delta13C $=-9,2 \%$ \%), или середина IV тыс. до н. э. Иначе говоря, данная кость не принадлежит к поздненеолитическому комплексу, а соответственно, у нас нет веских аргументов в пользу наличия скотоводства у местного населения в это время.
Эпоха энеолита в южной части Нижнего Поволжья представлена такими памятниками, как Курпеже-Молла, Кара-Худук, Каиршак VI, Комбактэ. На стоянке Курпеже-Молла были обнаружены керамика и каменный инвентарь, относимые к прикаспийской культу [3, с. 64]. Кроме того, в коллекции нами был выявлен ряд фрагментов, не относящихся к прикаспийскому типу. Например, черепки с примесью толченых раковин моллюсков, округлодонной формы сосудов, с орнаментом в виде рядов ногтевидных насечек, разделенных волнистыми линиями. Данная совокупность признаков характерна для посуды хвалынской культуры [4, с. 135]. Наряду с кварцитовым материалом, который традиционно считается прикаспийским, имеются находки из прозрачного темного и матового светло-серого кремня. Именно эти характеристики присущи в большей степени хвалынской культуре [6, с. 115]. Кроме сырья представлены изделия, типичные для орудийного набора данного типа: наконечник треугольной формы с усеченным основанием, концевые скребки на крупных пластинах [1, с. 121, рис. 25]. А из прозрачного темного кремня присутствуют «вкладыши», что демонстрирует сочетание микро- и макротехники. Таким образом, кроме керамического инвентаря хвалынской культуры представлены и каменные изделия, характерные для данного типа. Поэтому нельзя исключать, что кости домашней овцы, определенные П.А. Косинцевым на стоянке Курпеже-Молла [23, с. 69], могут относиться не к прикаспийской, а к хвалынской культуре. Единственным аргументом в пользу прикаспийской принадлежности доместицированной фауны может служить преобладание материалов данного типа над хвалынскими. Однако этот аргумент косвенный и нуждался в подтверждении. Оно появилось в результате новейших изысканий в Нижнем Поволжье. В решении этого вопроса большое значение приобретают материалы стоянки Орошаемое I в Саратовской области [16, c. 235-241]. Это единственный на данный момент памятник с сохранившимся в суглинке культурным слоем мощностью около 1 метpa. В нем была обнаружена воротничковая керамика и доминировали изделия из кварцита прикаспийской культуры. Если учесть, что материалы данной стоянки являются гомоген- 
ными, большое значение имеют определения фауны. На данном памятнике кроме костей диких животных были обнаружены останки домашних овцы и козы [16, с. 238]. Таким образом, можно констатировать, что признаки производящего хозяйства появляются уже у носителей прикаспийской культуры. Однако утверждать, что в данном случае мы имеем хронологический приоритет по сравнению с хвалынской культурой, было бы преждевременным. Имеющиеся радиоуглеродные даты для первой фиксируют хроноинтервал от 5000 до 4500 калиброванных лет. Что касается прикаспийской культуры, то ее хронологические рамки до недавнего времени определялись 5800-5000 лет ВС. По костям животных со стоянки Орошаемое I была получена радиоуглеродная дата $5667 \pm 100 \mathrm{BP}(\mathrm{Spb}$ (4700 ВC). В целях верификации на АМС были продатированы кости непосредственно домашней овцы - $5806 \pm 26$ (NSKA-1354) (4800 ВC). Более того, имеются подтверждения правильности полученных дат по стоянке Кумыска в Нижнем Поволжье, на которой по органике в керамике получена дата $5870 \pm 70$ (Ki-16271) ВР [22, с.115], полностью совпадающая с датами по стоянке Орошаемое I. Иначе говоря, даты для ряда памятников прикаспийской культуры соответствуют хроноинтервалу хвалынской культуры.

Таким образом, новейшие материалы неолита и энеолита по Нижнему Поволжью, а также современные методики их изучения позволяют сделать вывод о том, что признаки производящего хозяйства достоверно фиксируются в материалах прикаспийской культуры и датируются первой четвертью V тыс. до н. э.

\section{ПРИМЕЧАНИЕ}

1 Работа выполнена в рамках проекта 33.1195.2014/К государственного задания Министерства образования РФ.

\section{СПИСОК ЛИТЕРАТУРЫ}

1. Агапов, С. А. Хвалынский энеолитический могильник / С. А. Агапов, И. Б. Васильев, В. И. Пестрикова. - Куйбышев : Изд-во Сарат. ун-та, 1990.$160 \mathrm{c}$.
2. Барацков, А. В. Проблемы абсолютной хронологии неолита Северного Прикаспия / А. В. Барацков, А. А. Выборнов, М. А. Кулькова // Известия СНЦРАН. - Самара, 2012. - Т. 14, № 3. - С. 254-260.

3. Барынкин, П. П. Новые энеолитические памятники Северного Прикаспия / П. П. Барынкин, И. Б. Васильев // Археологические памятники на европейской территории СССР. - Воронеж : Изд-во ВГПИ, 1985.- С. 59-75.

4. Барынкин, П. П. Стоянка хвалынской энеолитической культуры Кара-Худук в Северном Прикаспии / П. П. Барынкин, И. Б. Васильев // Археологические культуры Северного Прикаспия. - Куйбышев : Изд-во КГПИ, 1988. - С. 123-141.

5. Барынкин, П. П. Энеолит и ранняя бронза Северного Прикаспия : автореф. дис. ... канд. ист. наук / Барынкин Павел Петрович. - М., 1992. - 26 с.

6. Барынкин, П. П. Энеолитический памятник Каиршак VI из южной части Волго-Уральского междуречья / П. П. Барынкин // Неолит и энеолит Северного Прикаспия. - Куйбышев : Изд-во КГПИ им. Куйбышева, 1989. - С. 106-117.

7. Васильев, И. Б. Энеолит Поволжья / И. Б. Васильев. - Куйбышев : Изд-во КГПИ, 1981. - 130 с.

8. Выборнов, А. А. Неолит Волго-Камья / А. А. Выборнов. - Самара : Изд-во Самар. гос. пед. ун-та, 2008. -490 с.

9. Выборнов, А. А. О корректировке абсолютной хронологии неолита и энеолита Северного Прикаспия / А. А. Выборнов, Н. Н. Ковалюх, В. В. Скрипкин // Труды II (XVIII) Всероссийского археологического съезда в Суздале, 2008 г. - Суздаль : Ин-т apx. PAH, 2014. - T. 1. - C. 191-193.

10. Гасилин, В. В. Фауна неолитической стоянки Варфоломеевская в степном Поволжье / В. В. Гасилин, П. А. Косинцев, М. В. Саблин // Фауна и флора Северной Евразии в позднем кайнозое. Екатеринбург ; Челябинск : Рифей, 2008. - С. 25-100.

11. Гречкина, Т. Ю. Новая ранненеолитическая стоянка Байбек в Северном Прикаспии / Т. Ю. Гречкина, А. А. Выборнов, Д. В. Кугуков // Изв. СНЦ РАН. - Т.16, № 3. - Самара, 2014. - С. 79-90.

12. Кольцов, П. М. Поселение Джангар / П. М. Кольцов. - М. : Новый Хронограф, 2004. - 156 с.

13. Мелентьев, А. Н. Памятники неолита Сев. Прикаспия (памятники прикаспийского типа) / А. Н. Мелентьев // Проблемы археологии Поволжья и Приуралья. - Куйбышев : Куйбышев. пед. ин-т, 1976. - С. 13-14.

14. Наумов, И. Н. Неолит Поволжско-Донских степей (проблемы хронологии, периодизации и культурно-хозяйственного развития) : автореф. дис. ... канд. ист. наук / Наумов Игорь Николаевич Воронеж, 2004. - $24 \mathrm{c}$.

15. Новые данные по радиоуглеродной хронологии неолита лесостепного и степного Повол- 
жья / А. А. Выборнов [и др.] // Изв. СНЦ РАН. Самара, 2013. - Т.17, № 3. - С. 254-260.

16. Новые материалы неолита Нижнего Поволжья / А. А. Выборнов [и др.] // Изв. СНЦ РАН. Самара, 2015. - Т. 17, № 3. - С. 235-241.

17. Синюк, А. Т. Проблемы хронологии неолита лесостепного Подонья / А. Т. Синюк // Проблемы хронологии и этнокультурных взаимодействий в неолите Евразии. - СПб. : Ин-т истории матер. культуры РАН, 2004. - С. 195-206.

18. Ставицкий, В. В. К вопросу о выделении неоэнеолитической эпохи в Поволжье / В. В. Ставицкий // Проблемы периодизации и хронологии в археологии эпохи раннего металла Восточной Европы. СПб. : Скифия-принт, 2013.- С. 31-33.

19. Телегин, Д. Я. О хронологии и периодизации культур неолита и медного века юго-запада Восточной Европы. Понятия о нео-энеолитическом времени региона / Д. Я. Телегин // Проблемы хронологии и этнокультурных взаимодействий в неолите Евразии. - СПб. : Ин-т истории матер. культуры РАН, 2004. - С. 106-121.

20. Юдин, А. И. Орловская культура и истоки формирования степного энеолита Заволжья / А. И. Юдин // Проблемы древней истории Северного Прикаспия. - Самара : Самар. гос. пед. ун-т, 1998.- C. 83-105.

21. Юдин, А. И. Периодизация и хронология энеолита степного Поволжья / А. И. Юдин // Проблемы периодизации и хронологии в археологии эпохи раннего металла Восточной Европы. - СПб. : Скифия-принт, 2013. - С. 26-30.

22. Юдин, А. И. Поселение Кумыска и энеолит степного Поволжья / А. И. Юдин. - Саратов : Научная книга, 2012. -212 c.

23. Vybornov, A. The origin of farming in the Lower Volga Region / A. Vybornov, P. Kosintsev, M. Kulkova // Documenta Praehistorica XLII. Ljubljana, 2015. - P. 67-75.

\section{REFERENCES}

1. Agapov S.A., Vasilyev I.B., Pestrikova V.I. Khvalynskiy eneoliticheskiy mogilnik [Eneolithic Khvalynsk Burial Ground]. Kuybyshev, Izd-vo Sarat. un-ta, 1990. $160 \mathrm{p}$.

2. Baratskov A.V., Vybornov A.A., Kulkova M.A. Problemy absolyutnoy khronologii neolita Severnogo Prikaspiya [Problems of Absolute Chronology of the Neolithic Northern Caspian]. Izvestiya SNTs RAN, 2012, vol. 14, no. 3, pp. 254-260.

3. Barynkin P.P., Vasilyev I.B. Novyie eneoliticheskie pamyatniki Severnogo Prikaspiya [New Eneolithic monuments of the North Caspian region]. Arheologicheskie pamyatniki na evropeyskoy territorii SSSR [Archaeological Monuments in the European Territory of the USSR]. Voronezh, Izd-vo VGPI, 1985, pp. 59-75.

4. Barynkin P.P., Vasilyev I.B. Stoyanka khvalynskoy eneoliticheskoy kultury Kara-Khuduk v Severnom Prikaspii [Site of Khvalynsk Eneolithic Culture of Kara-Khuduk in the North Caspian Region]. Arkheologicheskie kultury i Severnogo Prikaspiya [Archaeological Culture of the Northern Caspian]. Kuibyshev, Izd-vo KGPI, 1988, pp. 123-141.

5. Barynkin P.P. Eneolit $i$ rannyaya bronza Severnogo Prikaspiya: avtoref. dis. ... kand. ist. nauk [The Eneolithic and Early Bronze in the Northern Caspian Region. Cand. hist. sci. abs. diss.]. Moscow, 1992. 26 p.

6. Barynkin P.P. Eneoliticheskiy pamyatnik Kairshak VI iz yuzhnoy chasti Volgo-Uralskogo mezhdurechya [Eneolithic Monument of the CairoShaq 6 From the Southern Part of the Volga-Ural Interfluve Area]. Neolit i eneolit Severnogo Prikaspiya [The Neolithic and Chalcolithic of the Northern Caspian Region]. Kuibyshev, Izd-vo KGPI im. Kuybysheva, 1989, pp. 106-117.

7. Vasilyev I.B. Eneolit Povolzhya [The Eneolithic of the Volga Region]. Kuibyshev, Izd-vo KGPI, 1981. 130p.

8. Vybornov A.A. Neolit Volgo-Kamya [The Neolithic of the Volga-Kama Region]. Samara, Izd-vo Samar. gos. ped. un-ta, 2008. 490 p.

9. Vybornov A.A., Kovalyukh N.N., Skripkin V.V. O korrektirovke absolyutnoy khronologii neolita $\mathrm{i}$ eneolita Severnogo Prikaspiya [On the Adjustment of the Absolute Chronology of the Neolithic and Eneolithic of the Northern Caspian Region]. Trudy II (XVIII) Vserossiyskogo arkheologicheskogo syezda $v$ Suzdale, $2008 \mathrm{~g}$. [Proceedings of the II (XVIII) All-Russian Archaeological Congress in Suzdal, 2008]. Suzdal, In-t arkh. RAN, 2008, vol. 1, pp. 191-193.

10. Gasilin V.V., Kosintsev P.A., Sablin M.V. Fauna neoliticheskoy stoyanki Varfolomeevskaya v stepnom Povolzhe [Fauna of Neolithic Sites in Bartholomew Steppe in the Volga Region]. Fauna i flora Severnoy Evrazii v pozdnem kaynozoe [Fauna and flora of Northern Eurasia in the late Cenozoic]. Ekaterinburg; Chelyabinsk, Rifey Publ., 2008, pp. 25-100.

11. Grechkina T.Y., Vybornov A.A., Kutukov D.V. Novaya ranneneoliticheskaya stoyanka Baybek v Severnom Prikaspii [New early Neolithic Parking Baibek in the North Caspian region]. Izvestiya SNTS $R A N, 2014$, vol. 16, no. 3, pp. 79-90.

12. Koltsov P.M. Poselenie Dzhangar [Settlement Jangar]. Moscow, New Chronograph Publ., 2004. 156 p.

13. Melentyev A.N. Pamyatniki neolita Sev. Prikaspiya (pamyatniki prikaspiyskogo tipa) [Neolithic monuments of North. Caspian (monuments of the 
Caspian type)]. Problemy arkheologii Povolzhya $i$ Priuralya [Problems of archaeology of Volga and Ural regions]. Kuibyshev, 1976, pp. 13-14.

14. Naumov I.N. Neolit Povolzhsko-Donskih stepey (problemy khronologii, periodizatsii $i$ kulturno-khozyaystvennogo razvitiya): avtoref. diss. ... kand. ist. nauk [The Neolithic of the Volga-Don Steppes (Problems of Chronology, Periodization, and Cultural Economic Development). Cand. hist. sci. abs. diss.]. Voronezh, 2004. 24 p.

15. Vybornov A.A., Andreev K.M., Barankov A.V., Kulkova M.A., Koltsov P.M., Yudin A.I., Dzhall T., Goslar T., Oynonen M., Possnert G., Filippsen B. Novye dannye po radiouglerodnoy khronologii neolita lesostepnogo i stepnogo Povolzhya [New Data on Radiocarbon Chronology of Neolithic Forest-Steppe and Steppe of the Volga Region]. Izvestiya SNTs RAN, 2013, vol. 17, no. 3, pp. 254-260.

16. Vybornov A.A., Yudin A.I., Vasilieva I.N., Kosintsev P.A., Kulkova M.A., Goslar T., Doga N.S. Novye materialy neolita Nizhnego Povolzhya [New materials of the Neolithic age in the Lower Volga region]. Izvestiya SNTS RAN, 2015, vol.17, no. 3, pp. 235-241.

17. Sinyuk A.T. Problemy khronologii neolita lesostepnogo Podonya [The Problem of the Chronology of Neolithic Forest-Steppe Don Region]. Problemy khronologii i etnokulturnykh vzaimodeystviy $v$ neolite Evrazii [Problems of Chronology and Ethnocultural Interactions in the Neolithic of Eurasia]. Saint Petersburg, In-t istorii mater. kultury RAN, 2004, pp. 195-206.

18. Stavitskiy V.V. K voprosu o vydelenii neoeneoliticheskoy epokhi v Povolzhye [To the Question of the Allocation of the Neo-Eneolithic Era in the Volga Region]. Problemy periodizatsii $i$ khronologii $v$ arkheologii epokhi rannego metalla Vostochnoy Evropy [Problems of Periodization and
Chronology in Archaeology of the Early Metal of Eastern Europe]. Saint Petersburg, Skifiya-print Publ., 2013, pp. 31-33.

19. Telegin D.Ya. O khronologii i periodizatsii kultur neolita i mednogo veka yugo-zapada Vostochnoy Evropy. Ponyatiya o neo-eneoliticheskom vremeni regiona [About the Chronology and Periodization of Crops of Neolithic and Copper Age South-West of Eastern Europe. The Concept of NeoEneolithic Era of the Region]. Problemy khronologii $i$ etnokulturnykh vzaimodeystviy $v$ neolite Evrazii [Problems of Chronology and Ethnocultural Interactions in the Neolithic of Eurasia]. Saint Petersburg, In-t istorii mater. kultury RAN, 2004, pp. 106-121.

20. Yudin A.I. Orlovskaya kultura i istoki formirovaniya stepnogo eneolita Zavolzhya [Orlov Culture and the Origins of the Chalcolithic Steppe Trans-Volga region]. Problemy drevney istorii Severnogo Prikaspiya [Problems of Ancient History of the Northern Caspian]. Samara, Samar. gos. ped. un-t, 1998, pp. 83-105.

21. Yudin A.I. Periodizatsiya i khronologiya eneolita stepnogo Povolzhya [Periodization and Chronology of Bronze Age Steppe of the Volga Region]. Problemy periodizatsii $i$ khronologii $v$ arkheologii epokhi rannego metalla Vostochnoy Evropy [Problems of Periodization and Chronology in Archaeology of the Early Metal of Eastern Europe]. Saint Petersburg, Skifiya-print Publ., 2013, pp. 26-30.

22. Yudin A.I. Poselenie Kumyiska $i$ eneolit stepnogo Povolzhya [The Settlement of Comisca and Eneolithic Steppe of the Volga Region]. Saratov, Nauchnaya kniga Publ., 2012.212 p.

23. Vybornov A., Kosintsev P., Kulkova. M. The Origin ofFarming in the Lower Volga Region. Documenta Praehistorica XLII. Ljubljana, 2015, pp. 67-75.

\section{Information About the Authors}

Aleksandr A. Vybornov, Doctor of Sciences (History), Professor, Head of Department of Russian History and Archaeology, Volga Region State Academy of Social Sciences and Humanities, M. Gorkogo St., 65/67, 443099 Samara, Russian Federation, vibornov_kin@mail.ru.

Markku Oinonen, Doctor of Sciences, PhD, Laboratory Director, University of Helsinki, Gustaf Hallstromin St., 2, FL - 00014 Helsinki, Finland, markku.j.oinonen@helsinki.fi.

Natalya S. Doga, Master Student, Faculty of History, Research Assistant, Volga Region State Academy of Social Sciences and Humanities, M. Gorkogo St., 65/67, 443099 Samara, Russian Federation, natalidoga@yandex.com.

Marianna A. Kulkova, Candidate of Geological and Mineralogical Sciences, Associate Professor, Department of Geology and Geoecology, Herzen State Pedagogical University, r. Moyki Emb., 48/12, 191186 Saint Petersburg, Russian Federation, kulkova@mail.ru.

Aleksandr S. Popov, Master Student, Faculty of History, Volga Region State Academy of Social Sciences and Humanities, M. Gorkogo St., 65/67, 443099 Samara, RussianFederation, asya.samara@gmail.com. 


\section{Информация об авторах}

Александр Алексеевич Выборнов, доктор исторических наук, профессор, заведующий кафедрой отечественной истории и археологии, Поволжская государственная социально-гуманитарная академия, ул. М. Горького, 65/67, 443099 г. Самара, Российская Федерация, vibornov kin@mail.ru.

Маркку Ойнонен, доктор наук, доцент, руководитель лаборатории, университет Хельсинки, ул. Густафа Халльстрёма, 2, FL - 00014 г. Хельсинки, Финляндия, markku.j.oinonen@helsinki.fi.

Наталья Сергеевна Дога, магистрант исторического факультета, лаборант научно-исследовательской части, Поволжская государственная социально-гуманитарная академия, ул. М. Горького, 65/67, 443099 г. Самара, Российская Федерация, natalidoga@yandex.com.

Марианна Алексеевна Кулькова, кандидат геолого-минералогических наук, доцент кафедры геологии и геоэкологии, Российский государственный педагогический университет, наб. p. Мойки, 48/12, 191186 г. Санкт-Петербург, Российская Федерация, kulkova@mail.ru.

Александр Сергеевич Попов, магистрант исторического факультета, Поволжская государственная социально-гуманитарная академия, ул. М. Горького, 65/67, 443099 г. Самара, Российская Федерация, asya.samara@gmail.com. 